\section{The role of library user preferences in the willingness to read and pay for e-books: case of the Czech Republic}

Role of library user preferences

\author{
Jan Stejskal
}

\author{
Faculty of Economics and Administration, Masaryk University, \\ Brno, Czech Republic, and \\ Petr Hajek and Viktor Prokop \\ Faculty of Economics and Administration, \\ University of Pardubice, Pardubice, Czech Republic
}

Received 12 January 2021 Revised 9 March 2021 9 April 2021 Accepted 28 April 2021

\begin{abstract}
Purpose - The study aims to analyse library user preferences in the willingness to read and pay for ebooks, using a sample of both active readers (users of public library services) and non-users (the general population).

Design/methodology/approach - Two empirical surveys were conducted from August to November of 2019; the research sample consisted of 1,334 users from the Municipal Library of Prague and 1,101 non-users from the general Czech population. The research was focussed on e-book user preferences. The willingness to pay (WTP) for e-book services and the determinants that affect this willingness were also examined.

Findings - The results show the specific approach of Czech readers, whose main determinant of WTP is not the content, but the price and method of its payment (allocation). Some people prefer a cheaper annual lump sum, whereas others may prefer a charge of small regular fees. The decision to pay depends on their reading or payment habits.

Originality/value - This study also aims to clarify the demand for various types of digital media in Czech libraries and the preferred distribution models. Furthermore, the study determines the dependence of the preferences of library users in their WTP for e-books using different evaluation models. The originality of this study is in the evaluation of the determinants of WTP for e-books, which makes this study unique, and the findings should contribute to the expansion of existing knowledge in the field of information science.
\end{abstract}

Keywords Library users' preferences, Willingness to pay, E-books, Readers, Non-users, Czech Republic

Paper type Case study

\section{Introduction}

A number of popular media and research studies are currently discussing a change in user behaviour, namely, whether the change in maturity and the development of information

(C) Jan Stejskal, Petr Hajek and Viktor Prokop. Published by Emerald Publishing Limited. This article is published under the Creative Commons Attribution (CC BY 4.0) licence. Anyone may reproduce, distribute, translate and create derivative works of this article (for both commercial and noncommercial purposes), subject to full attribution to the original publication and authors. The full terms of this licence may be seen at http://creativecommons.org/licences/by/4.0/legalcode 
$\mathrm{EL}$ 39,4

technology (IT) are gradually changing users' habits (Noh, 2020). This question also applies to the cultural industry, including books. The digital revolution is forcing fundamental debates in this area. The discussion explores the justification of the existence of paper books (printed books) and their gradual replacement with electronic books (Lin et al., 2019; Rao et al., 2018; Richter and Courage, 2017; Salloum and Shaalan, 2018; among others). The "fight" between e-books and printed books has been going on since the 1990s (the first Sony e-reader was created in 1992; Catenazzi, 1997; Vassiliou and Rowley, 2008). At that time, the development of e-books was perceived as a major threat to printed books. Some studies have seen gradual changes in some countries (Jeong, 2012; Pew Research Center, 2014; Wang et al., 2019; Zhu, 2015) in favour of e-books. Some companies have seen a higher share of interest in e-books. For example, US markets have seen a significant increase in interest in e-books due to the newly introduced Kindle e-readers, resulting in year-over-year sales growth in tens of percent (Shim et al., 2016). Interestingly, the same surveys also show that printed books are still part of readers' habits. In the case of the US book market, only $4 \%$ of readers stopped using paper books and fully replaced them with e-books (Pew Research Center, 2014). The rest use e-books in combination with paper books.

Library users' (mainly readers) behaviour is determined not only by individual preferences, but also by strategic behaviour on the supply side - most often, publishers. For them, e-book publishing is far more efficient, so they a greater effort to promote e-book subscriptions, time subscriptions, or loans of readers to remove the barrier to accessing ebooks. Most of the world's publishers (e.g. Forbes, Scribd, Springer, EE) have already moved to expand the offerings of electronic books over paper books. Of course, these publishers also address the issue of copyright protection, the technical security of digital services, and the reduction of computing power requirements so that virtually anyone can read the ebook. From a marketing point of view, publishers are also entering a whole new market, where they have no other interaction with the patrons than through applications, online advertising, and so forth. Thus, even these companies need to understand how to get satisfied users to buy and pay for e-books (Huang et al., 2017). However, there is often no massive adoption of e-books, but rather a dilution of demand or just the necessary library user behaviour (because the paper book is not available on the market).

Thanks to the development of digital services, there is a significant expansion of the offer of so-called digital documents that were not previously accessible due to their high historical value or the threat of destruction during further use. These include mainly maps, historical books, archival documents, and so forth. Such documents are mostly provided by public or state organizations; namely, libraries. The offer is realized due to public interest and is usually financed with public funds, so library users often do not pay any fees for using such services.

Thus, further research into user behaviour in the e-book and printed book market is necessary. In particular, the impact of digital technologies on user behaviour needs to be clarified and economic aspects addressed. User behaviour in virtual markets (on the Internet) is changing significantly. Users are willing to pay for digital services and, as a result, are far more advanced and able to compare the benefits they get with the costs they have to bear (Chen, 2012). These experiences are also becoming an important determinant of user behaviour.

For e-book producers as well as libraries, it is essential to distinguish the demand of paper book readers or e-book readers from those who are not active visitors to libraries or active readers (i.e. the general population), as these people probably have different requirements for a printed book or e-book, so their behaviour will differ (Chow and Tian, 2021). Yet very few studies have defined, analysed, and examined the role of user 
preferences in the provision of information e-services. The aim of this study is to analyse the preferences of e-book users using a sample of both active readers (public library users) and non-users (the general population). This study also aims to clarify the demand for various types of digital media in Czech libraries and their preferred distribution models. Furthermore, the study determines the dependence of user preferences in willingness to pay (WTP) for e-books using different evaluation models. The novelty of this study is in the evaluation of the determinants of WTP for e-books, which makes this study unique, and the findings should contribute to the expansion of existing knowledge in the field of information

Role of library user preferences science.

The remainder of this paper is structured as follows. In Section 2, the theoretical background for empirical surveys and behaviour analyses of readers and non-users as a specific focus (target) group is presented. Section 3 provides the methodology of the empirical survey. Section 4 provides the characteristics of the data set and the research results. In Section 5, the obtained results are discussed, and Section 6 concludes the paper with suggestions for future research.

\section{Theoretical background and hypothesis development}

\subsection{Literature review on e-book user behaviour}

In the past two decades, there has been a significant increase in digitization in all areas of human activity. The same trend is evident in the field of cultural services, especially in public libraries, as well as academic libraries. With the development of IT and communications, technical barriers to the expansion of the offer of books in digital form are being fundamentally removed (Hawkins, 2002). It might seem that if technical barriers are removed, a massive supply will be created (public libraries and e-book producers) to which demand by readers will respond. Trends in the introduction of e-books into library collections and commercial offers of e-books are evolving, but these trends show some variability (Ashcroft and Fong, 2005). The largest offer of electronic content (whether e-books or e-journals) are from academic libraries, with demand created by students and scientists (especially in technical and scientific fields). However, offers have gradually expanded to include fiction, textbooks and other genres (Ashcroft, 2011).

Despite the massive development of digital technologies, which significantly affect the lives of each individual, various determinants of user behaviour (readers of e-books or printed books and documents) remain. Some of them are users' fundamental determinants, which can be called "mental obstacles". An example of such an obstacle is the experience of reading a book. According to many studies, this experience depends on the form of the book (e-book or printed book). Godwin-Jones (2007) concluded that the experience of reading an ebook is comparable to the experience of reading a printed book. One of the strong promoters of e-books was Sottong (1999), who argued that "the best display technology cannot beat print on paper" (p. 50). However, many scholars disagree (Chu, 2003; Sellen and Harper, 2003) who claim that a printed book has certain elements that can never be replicated in an e-book. They refer to them as affordances, or a set of properties that bring a special kind of benefit (experience, feeling) to the reader. Specifically, readers can feel the paper in their hands, along with the smell of a printed book, which combine with memories and experiences in the human psyche that have a high personal emotional value for users. This group of readers will therefore dominate and will not be willing to switch to e-books completely.

On the other hand, a number of studies (Cumaoglu et al., 2013; Dillon, 2001; Prokop and Stejskal, 2020) have focussed on the behaviour of readers (of either e-books or printed books) to define the requirements that an e-book must have in order for readers to be willing to 
$\mathrm{EL}$ 39,4

accept it as a medium for reading and at the same time be willing to pay for access. Schilit (1999) described the six advantages that e-books have. He considered the mobility of the ebook and the ability of the publisher to distribute it through various distribution channels to be essential. In terms of user functions, it most often supports the function of full-text search and filtering. Berry et al. (2002) added that readers especially appreciate post-benefit convenience. In line with these conclusions, Lai and Chang (2011) defined the requirements as follows: an e-book can be read comfortably, anywhere, and it must be compatible with the paper book (thus providing the same content, including graphic pages). Its advantage is the possibility of hyperlinking, which allows the reader to easily switch to new content according to the reader's interest.

Some studies have examined the situation on the part of the reader and analysed the reasons there is no wider demand for e-books. Interestingly, research conclusions have not changed significantly, although several decades have passed between their publications. Sainsbury (1996) concluded that barriers to more massive use of e-books are the unavailability of hardware (e-readers), financial demands, and the health problems caused by screen work. Health risks and the quality of e-books no longer appear to be an issue. Kim et al. (2020) identified four barriers to a wider e-book spread - namely, usage, value, risk, and image - that cause resistance to change, and readers with a higher resistance have a lower intention to use e-books. Foasberg (2011) identified obstacles by focusing on the basic premise of reading e-books (that is, with an e-reader) and, according to Foasberg's results, the basic obstacles are the price of the e-reader as well as the available selection on the market. The price of an e-book and the possible price of a substitute in the form of a printed book were rated in third place. The logical conclusion is that those who do not own an e-reader automatically prefer a printed book.

\subsection{Hypothesis development}

The very requirements for e-books are an important determinant of reader behaviour (Martindale et al., 2015). In a study by Chou et al. (2010), they concluded by stating "potential adopter intention to adopt is solely determined by normative pressures, whereas user intention is solely determined by attitude, which refers to the perception of content enrichment, reading servicisation, and device personalization” (p. 854). Carroll et al. (2016) postulated the same conclusion. This normative intention is determined by individual preferences. Kurata et al. (2017) published research that also focused on e-book usage and preferences. Their research is based on a broad definition of reader preferences, which are based on a certain limited rationality and each reader's ability to choose an advantageous (effective) variant for themselves. Models working with these assumptions have been used in many studies (Bansal, 2011; Davis, 1989; Rogers, 2003). This assumption will also be applied in this research and the results published in this paper.

Likewise, a certain soft prerequisite is a certain user setting. Shrimplin et al. (2011) defined several users according to their methodology, finding that their preferences and normative behaviour were very similar. One group is "book lovers", who in all circumstances prefer physical objects in hand (e.g. printed books), whereas "technophiles" always favour e-books for their accessibility to the search function - a feature essential for them that surpasses all negatives and obstacles. "Pragmatists" behave according to the occasion and in all circumstances choose the more effective variant (typically, if they need to travel, they choose an e-book due to its low weight). The last group consists of those readers who, for health reasons, have difficulty reading from the screen. They are called "printers". It is already clear from this study that some users will never prefer e-books. 
Based on the above literature review, the following hypotheses are formulated:

H1a. E-book preferences (in terms of preferred ways of obtaining books, and devices used for reading e-books) differ across age categories.

$H 1 b$. E-book preferences (in terms of preferred ways of obtaining books, and devices used for reading e-books) differ for the general population and readers at the Municipal Library of Prague (MLP).

Different groups of e-book readers create demand, and the volume of this demand is influenced by various factors which need to be analysed according to each group's willingness to request access to a printed book or e-book. A number of studies have addressed the WTP for the provision of books (Fujiwara et al., 2019; Lee and Chung, 2012; Stejskal et al., 2016) and e-books (Ahmad and Brogan, 2016; Min et al., 2011; Stejskal and Hajek, 2015). All studies concluded that regular readers (e.g. those registered in a library) are more willing to pay to borrow a book due to the habits associated with regular library attendance and regular reading (Cameron, 2019; Kim, 2011).

In their study conducted in the USA, Chow and Tian (2021) found that non-users are positively affected by the existence of a public service, namely, a library where they can borrow books. The positive impact of this service was identified in terms of quality of life, level of education, average per capita income, and number of jobs. The scholars pointed out that the role of libraries defined in this way justifies the public interest in their existence. Therefore, the following hypotheses are formulated:

H2a. Demand for e-books differs across age categories.

H2b. Demand for e-books is different for the general population and readers at the MLP.

However, previous studies have rarely examined whether library readers and non- users would be willing to pay for the provision of a public service or the availability of paper books or e-books. For example, Liu et al. (2020) analysed the changes in readers' interest in e-books when they were provided for free or for a cost on Zongheng.com (a well-known online reading platform in China). They stated that information cascades are more salient for paid e-books than for free e-books. (Information cascades are a new phenomenon resulting from the study of behavioural economics and network theory, according to which many people gradually make the same decisions. It is, therefore, a study of patterns of user behaviour.) A similar study which dealt with information provision in South Korea via mobile instant messenger, not e-books, examined an employed WTP approach and confirmed that informational messages bring greater benefits than costs to readers (Kim, 2018). In general, this service provides a higher net social benefit, which justifies its existence and financing. It can be assumed that occasional users will be less WTP for books (printed books or e-books) because they have not yet perceived the need in their lives. This is confirmed by the findings of Kendall (1996), Ko et al. (2012), Sin and Vakkari (2015), and Wadley et al. (1997). So, additional hypotheses are proposed as follows:

H3a. WTP for e-book loans and downloads differs across age categories.

$H 3 b$. WTP for e-book loans and downloads is different for the general population and readers at the MLP.

\section{Research methodology}

To investigate the role of user preferences in WTP for e-books, two empirical surveys from August to November of 2019 were conducted. The first survey focussed on the general
Role of library user preferences

$-2$ 
$\mathrm{EL}$ 39,4

population, whereas the second one was intended for readers at the MLP (the largest municipal library in the Czech Republic, with 43 branches, 1.8 million visits per year, 5 million books borrowed, and 2.8 million e-books downloaded in 2019). Both surveys were carried out using an online computer-assisted Web interviewing (CAWI) questionnaire.

To obtain reliable and representative results, quota sampling was used for the general population survey. Age category, education level, and gender were used as quotas based on the Czech Statistical Office data. The online Czech National Panel was used to sample respondents. The sample of respondents for the second survey were the readers of the MLP, aged $18+$ years, with an e-mail address. The respondents were randomly selected from the library database of readers. An individualized e-mail was sent to each respondent along with a unique link to the questionnaire. The questionnaire was forwarded to 7,847 readers and 1,334 responded, generating a $17 \%$ rate of return. Detailed survey information is presented in Table 1.

The questionnaire for the general population was structured into five main sections: reading print books; preferred ways of obtaining books; reading e-books; demand and WTP for e-book loans and downloads; and reasons for not using e-books. The questionnaire used for the sample was slightly modified to consider e-book services provided by the MLP.

\section{Results}

Concerning the basic demographic statistics of the sample, $51 \%$ of the respondents were men, and the average age of the respondents was 48.1 years. In addition, $72 \%$ and $13 \%$ of the respondents had secondary and university education, respectively. About half of the respondents were economically active and $30 \%$ were retired. More details on the descriptive statistics of the sample are provided in Appendix. The use of quota sampling for the general population survey ensured that these statistics agree with those for the Czech population. In contrast, the demographic statistics for the sample of the readers of the MLP follow the structure of its registered readers, which includes a lower percentage of men (22\%) and a higher education level (56.7\% with university education).

The first part of the research concerned distribution channels; namely, the preferred ways to obtain books (both paper and e-books). All respondents in the target group answered. When asked about the preferred ways of obtaining a book, they had the opportunity to state two options (ways) and their order (Table 2). Respondents most often bought books and preferred printed books. Another option is to borrow the book from the library or from relatives. Very few respondents answered that the first or second choice was to buy/borrow an e-book. This quite significantly describes the respondents' relationship to paper books and the specifically low popularity of e-books among Czech readers.

Among respondents who ranked any way to obtain an e-book as first, the most preferred ways to obtain e-books were further explored among different age categories. The results in Table 3 show the traditional effort to obtain e-books on the internet (free of charge) or from the library (free of charge). Buying or borrowing an e-book (usually associated with a small

Table 1.

Survey information

\begin{tabular}{lll}
\hline Characteristics & General population & Readers from the MLP \\
\hline Sample size & $N=1,101$ & $N=1,334$ \\
Sample selection & Quota sampling & Random sampling \\
Data collection method & Online survey CAWI from online panel & Online survey CAWI \\
Average time to fill out the questionnaire & 9 min and 2s & 9 min and 12s \\
Data collection & November 2019 & August 2019 \\
\hline
\end{tabular}


fee) is the least preferred option. Thus, readers behave in such a way as to obtain an e-book while simultaneously avoiding paying. Therefore, it is necessary to further address the determinants of behaviour and determine whether the behaviour of regular library visitors and the general population differs significantly.

The first crucial determinant that fundamentally influences reader behaviour is their age. Many studies have found that the information society is determined by age-related information literacy. This assumption was also confirmed by the research of readers in the basic group, where those most willing to read e-books were economically active between the

Role of library user preferences

645 ages of 26 and 65, followed by students and finally pensioners (Figure 1). The low proportion of students is surprising and can be explained by the fact that the Czech educational system rarely works with e-books.

\begin{tabular}{lll}
\hline Answer & $\operatorname{Rank} 1[\%]$ & $\operatorname{Rank} 2[\%]$
\end{tabular}

Purchase a new print book

Purchase a used print book (in a bookstore, e-shop, etc.)

Borrow a print book from relatives, etc.

Borrow a print book from a library

Buy an e-book

Borrow an e-book from a library

Download a free e-book from the library website

Obtain a free e-book somewhere else on the Internet

Otherwise

$\begin{array}{rr}37 & 14 \\ 11 & 18 \\ 15 & 27 \\ 20 & 16 \\ 2 & 3 \\ 3 & 5 \\ 5 & 8 \\ 6 & 7 \\ 1 & 1\end{array}$

Table 2.

Preferred way of obtaining books

\begin{tabular}{|c|c|c|c|c|c|}
\hline \multirow[b]{2}{*}{ Answer } & \multicolumn{4}{|c|}{ Age category } & \multirow{6}{*}{$\begin{array}{r}\text { Table } 3 . \\
\text { The most preferred } \\
\text { way (Rank 1) of } \\
\text { obtaining e-books for } \\
\text { different age } \\
\text { categories }\end{array}$} \\
\hline & $18-25$ & $26-45$ & $46-65$ & $>65$ & \\
\hline Buy an e-book & 1.0 & 1.8 & 2.8 & 3.3 & \\
\hline Borrow an e-book from a library & 1.0 & 3.6 & 3.2 & 3.3 & \\
\hline Download a free e-book from the library website & 5.2 & 5.8 & 5.2 & 4.6 & \\
\hline Obtain a free e-book somewhere else on the Internet & 6.3 & 5.1 & 5.6 & 5.9 & \\
\hline
\end{tabular}

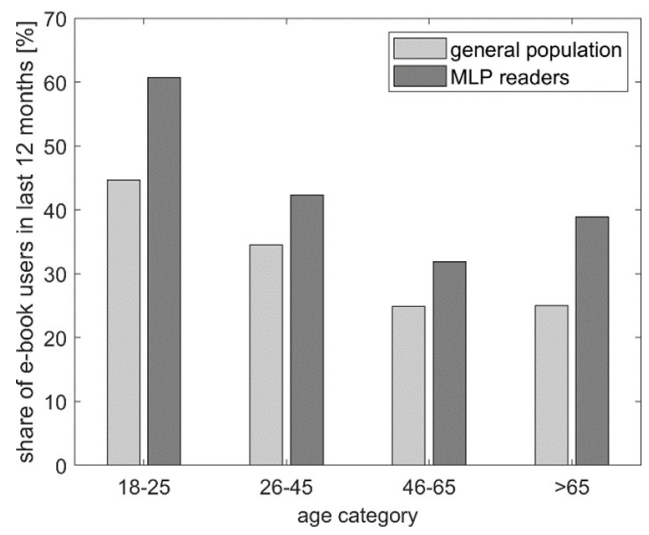

Figure 1.

Have you used any e-books in the last 12 months? 
EL

39,4

646

An important follow-up question was the number of e-books that the reader used in the previous 12 months. The results showed that the average number of books in all categories was approximately five for this timeframe (Figure 2). Other results support the previously described results. An exception is the category of pensioners; when they were able to read e-books, they read more than students.

For information society support, it is essential to know the source of the e-books that users obtain (Figure 3). Economically active respondents are willing to buy e-books to a small extent (maximum 20\% of respondents). Most of the basic file can be downloaded for free from the Internet, which is in line with previous research (Stejskal and Hajek, 2015). It is less gratifying that public libraries in the Czech Republic play only a marginal role in the development of the information society; despite a relatively wide range of available e-books, very few readers download e-books from the libraries' websites. Students are more interested in e-books, which corresponds to the obligation to read a certain number of books for the leaving examination. In addition, it is possible to deduce from the answers that the methods of promotion or the technical side of downloading e-books are not user friendly for older age groups.

The results also confirmed that most respondents used e-books for relaxation and entertainment. Only a relatively small number of the respondents needed them for their jobs or business; they looked for professional publications (in the group of economically active, more than $10 \%$ of the sample used e-books for this reason). The results of the popularity of genre readers read as an e-book also corresponded to this finding. E-books are most often used as a source of foreign fiction and professional literature (approximately 60\% of all respondents, regardless of age category). This result can, therefore, be used by public libraries for acquisition management.

An important piece of information is the result concerning the technical equipment that respondents use to read e-books (Figure 4). The most used equipment is smartphones, tablets, and computers. E-book readers are used only marginally.

\subsection{Respondents: e-book non-users}

An e-book non-user refers to respondents who indicated on the survey that they had not downloaded or read any e-book in the preceding 12 months. The first logical question for these respondents is why they do not use e-books. The results are provided in Table 4.

\section{Figure 2.}

Number of e-books borrowed in the last 12 months

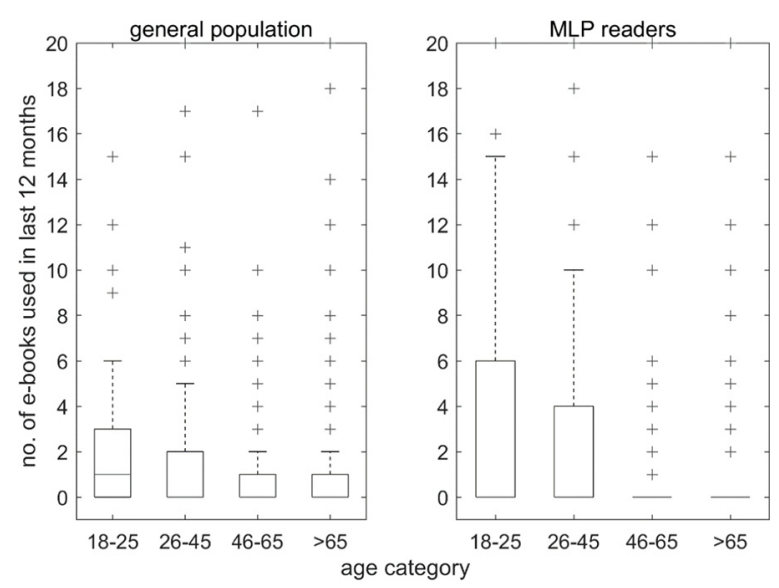




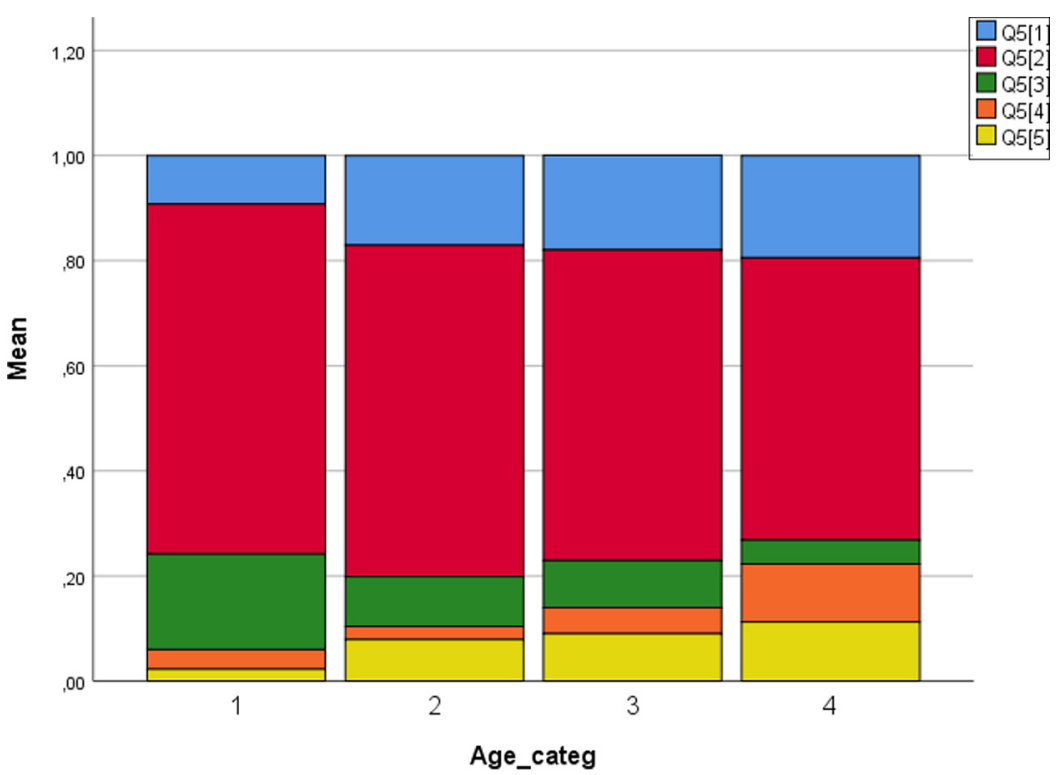

Notes: 1) buy in an e-shop; 2) download free from the internet; 3) download free from a public library website; 4) loan from a public library website (only for registered readers); 5) another way

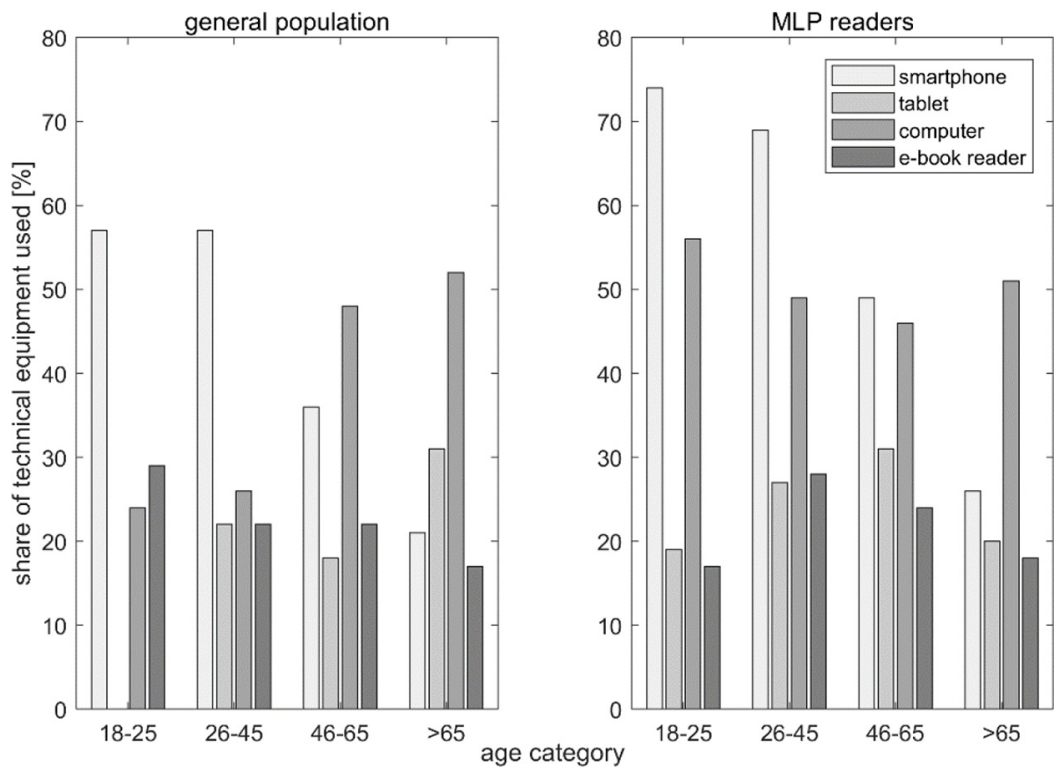

Role of library user preferences

Figure 3. Source of e-books

Figure 4.

Which of the following devices do you usually use to read e-books? 
EL

39,4

\section{8}

The most common answer in all age groups was that respondents did not read books at all. The second most common reasons were the need to "hold a paper book in their hands" and the need to "smell and feel the paper". This is a large sentimental group of readers who do not like electronic devices for leisure reading. The views of these respondents - potential readers - also need to be considered. Other options are marginal.

The second question asked of e-book non-users concerned their willingness to read e-books in the future (in the next 12 months; Table 5).

The results are not very encouraging. Most respondents did not feel motivated to read e-books. This result should be seen as a challenge for e-book producers and the public libraries that loan e-books. An empirical survey should be conducted among non-users to determine what needs to happen to motivate them to read e-books. Barriers to reading e-books include using IT technologies in other areas, such as e-government or other e-public services.

In existing research, the researchers have focused on only one potential barrier - most often the lack of availability of IT technology or equipment on which e-books can be read. Therefore, the question of the preference for e-reading followed.

Youth read e-books using a smartphone, a tablet, or a laptop or PC, with an e-book e-reader being ranked last. Figure 5 shows the correlation between age and willingness to use IT equipment. Among Czech pensioners, the most widespread IT tool used is a computer or tablet, which pensioners would consider as a device for reading e-books. It is clear from this that IT literacy and the availability of appropriate equipment fundamentally affect both people's access to e-books and e-information and their willingness to read e-books in an electronic form.

Table 4.

Reasons why respondents did not use e-books

\begin{tabular}{lrrrrrrrrr}
\hline & \multicolumn{3}{c}{ General population } & \multicolumn{7}{c}{ MLP readers } \\
Reason & $18-25$ & $26-45$ & $46-65$ & $>65$ & $18-25$ & $26-45$ & $46-65$ & $>65$ \\
\hline I do not read any books & 3.9 & 6.2 & 1.3 & 0.0 & 0.0 & 1.7 & 0.0 & 0.0 \\
I like paper books & 80.0 & 87.7 & 81.9 & 87.8 & 90.9 & 89.8 & 89.4 & 86.4 \\
I need to flip through the book & 44.0 & 50.0 & 45.0 & 50.0 & 81.8 & 54.2 & 44.7 & 52.3 \\
I need to make notes in a book & 4.0 & 6.6 & 8.1 & 7.3 & 18.2 & 3.4 & 4.3 & 4.6 \\
I like the smell and feel of paper & 52.0 & 41.8 & 23.5 & 17.1 & 63.6 & 37.3 & 31.9 & 18.2 \\
I do not have the appropriate equipment & 8.0 & 9.8 & 20.1 & 29.3 & 27.3 & 18.6 & 12.8 & 15.9 \\
I want a rest from PC screens & 60.0 & 43.4 & 38.3 & 29.3 & 68.2 & 45.8 & 36.2 & 52.3 \\
I don't know how to work with e-books & 4.0 & 3.3 & 7.4 & 14.6 & 4.6 & 3.4 & 12.8 & 13.6 \\
I don't know how to get e-books & 4.0 & 1.6 & 4.7 & 7.3 & 13.6 & 3.4 & 4.3 & 9.1 \\
The e-books I want to read are not available & 12.0 & 2.5 & 3.4 & 8.5 & 0.0 & 3.4 & 2.1 & 2.3 \\
\hline & & & & & & & & &
\end{tabular}

Table 5.

Do you plan to read any e-book in the next 12 months? [\%]

\begin{tabular}{lrrrrrrrr}
\hline & \multicolumn{9}{c}{ General population } & & \multicolumn{4}{c}{ MLP readers } \\
Answer & $18-25$ & $26-45$ & $46-65$ & $>65$ & $18-25$ & $26-45$ & $46-65$ & $>65$ \\
\hline Certainly yes & 7.7 & 3.1 & 4.6 & 0.0 & 13.6 & 5.0 & 0.0 & 2.3 \\
Rather yes & 30.8 & 20.2 & 19.9 & 14.8 & 18.2 & 20.0 & 17.0 & 20.5 \\
I don't know & 15.4 & 17.1 & 13.9 & 13.6 & 9.1 & 20.0 & 8.5 & 20.5 \\
Rather not & 38.5 & 40.3 & 39.7 & 51.9 & 40.9 & 43.3 & 57.4 & 47.7 \\
Certainly not & 7.7 & 19.4 & 21.9 & 19.8 & 18.2 & 11.7 & 17.0 & 9.1 \\
\hline
\end{tabular}




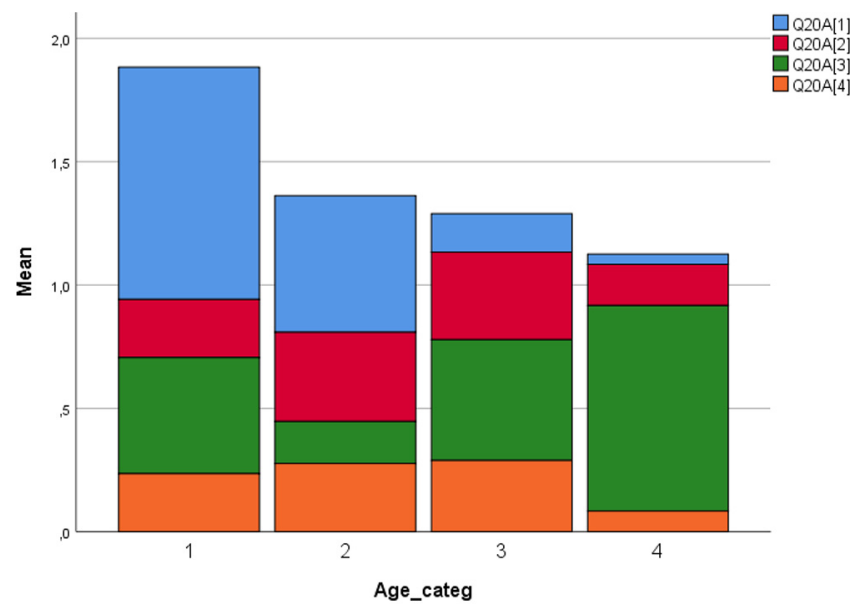

Notes: 1) A smartphone; 2) a tablet; 3) a laptop or PC; and 4) an e-book reader
Role of library user preferences

649

Figure 5.

Which of the electronic devices would you most likely use to read ebooks?

\subsection{Willingness to pay for e-book services}

One of the key determinants of a willingness to read e-books is their price and readers' WTP for them. The results of the research highlight the willingness of Czech readers depending on their age group.

The first question concerned the possibility of borrowing an e-book for reading on a PC, tablet, or smartphone for 30 days. Respondents commented on whether they would be interested in such a service for free (Table 6).

Respondents across age groups answered mostly positively. A certain percentage of staunch opponents of e-books (identified as sentimental readers who require a paper book for maximum experience) is evident.

The same question was again asked, but this time with an e-book borrowing service charging a fee. To evaluate the effect of the fee on the willingness to borrow an e-book, Chisquare tests were performed. The results indicated that the introduction of a fee significantly affected the decision of all age groups except young readers (18-25 years).

A very small number of student and pensioner readers responded positively, which is mainly due to their social situation. A relatively high WTP for e-books was recorded among younger, economically active workers. A negative response was noted in approximately half of the respondents in the two oldest age groups (Figure 6). In this context, it should be noted

\begin{tabular}{|c|c|c|c|c|c|c|c|c|c|}
\hline \multirow[b]{2}{*}{ Answer } & \multicolumn{4}{|c|}{ General population } & \multicolumn{4}{|c|}{ MLP readers } & \multirow[b]{2}{*}{ Table 6.} \\
\hline & $18-25$ & $26-45$ & $46-65$ & $>65$ & $18-25$ & $26-45$ & $46-65$ & $>65$ & \\
\hline Certainly yes & 11.5 & 15.0 & 9.0 & 4.6 & 34.3 & 27.4 & 25.3 & 21.9 & Would you be \\
\hline Rather yes & 26.2 & 23.8 & 22.7 & 16.4 & 8.4 & 7.9 & 8.3 & 10.0 & interested in \\
\hline I don't know & 8.2 & 13.2 & 15.7 & 15.1 & 15.1 & 14.4 & 12.0 & 18.1 & borrowing an e-book \\
\hline Rather not & 42.6 & 31.1 & 31.7 & 40.1 & 3.3 & 3.1 & 3.5 & 5.4 & for 30 days for free? \\
\hline Certainly not & 11.5 & 16.8 & 21.0 & 23.7 & 38.9 & 47.3 & 51.0 & 44.6 & {$[\%]$} \\
\hline
\end{tabular}


EL

39,4

650

Figure 6.

Would you be interested in borrowing an e-book for 30 days for a fee?

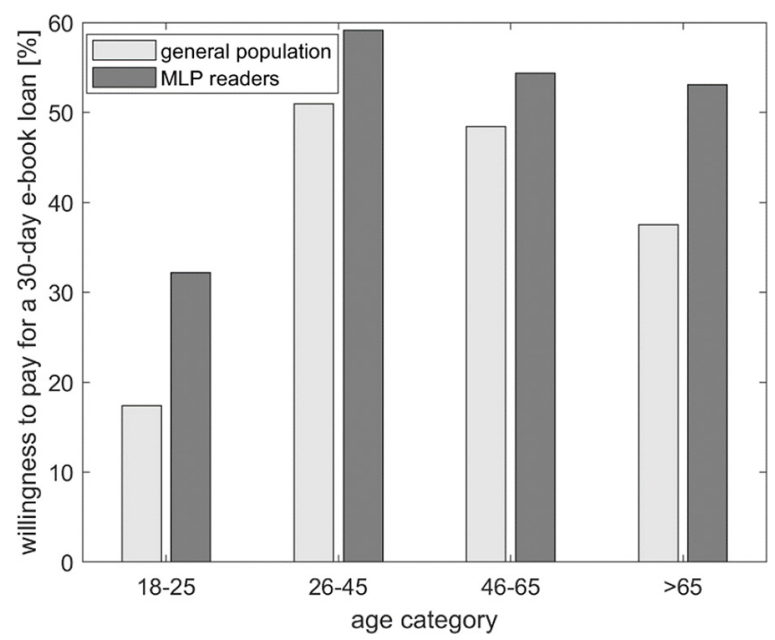

that WTP could correlate not only to whether respondents are economically active or retired, but also to salaries earned.

For practical use, the most interesting answer is the WTP for one e-book for one month. The answers of those who were willing to pay are shown in Figure 7.

The results showed that the WTP is limited to a maximum of CZK 50 per book per month (approximately 2 EUR), ranging between 0 and $100 \mathrm{CZK}$. The willingness decreases with increased age. An interesting finding is that the youngest respondents perceived the highest value of e-books (probably due to their knowledge of the value of other e-products, such as computer games or e-music).

The researchers hypothesized that "temporariness" (a one-month loan period) may also play a significant role in the WTP for an e-book. Therefore, respondents were asked about their WTP for downloading one e-book from the public library website.

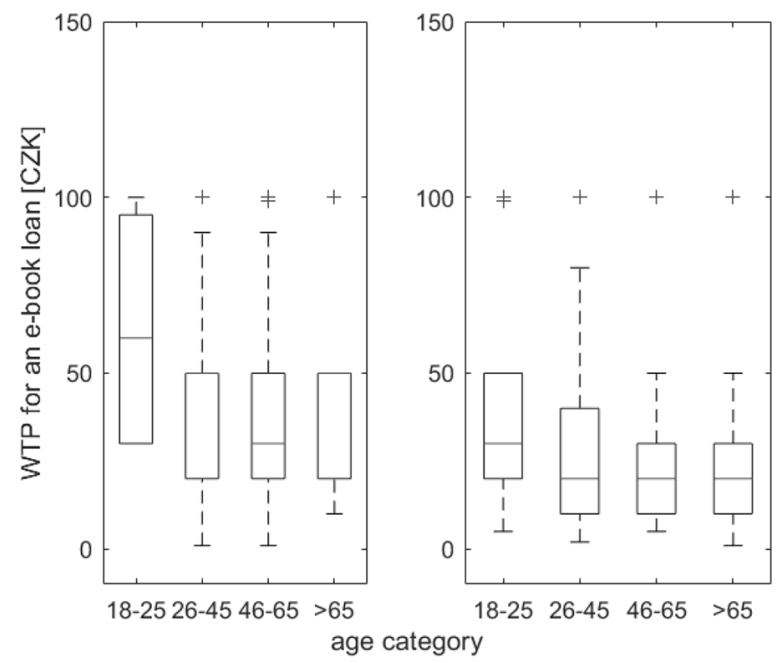

Figure 7.

How much would you be willing to pay for one e-book borrowed for one month? 
The results confirmed the assumption that the "temporariness" of borrowing significantly reduces the WTP. This is a completely rational tendency confirmed by the results in Figure 8. The amount for permanently obtaining an e-book from the public library website has increased in all categories. For the youngest category, the maximum increased to CZK 100 , while the average value was CZK 42.3 .

An important part of the analysis was identifying the determinants that affect users' WTP to borrow an e-book. An overview of the results is provided in Table 7. The results indicate that user behaviour is influenced by many factors and cannot be easily included in a single analysis, but the fundamental determinant was sex and education as well as the need to obtain a book for professional use.

Surprisingly, the results, compared to those of other studies, did not confirm the effect of economic activity, age, or income. Based on the presented results, further research is necessary in order to analyse individual categories of users separately as well as a wider range of WTP determinants specifically defined for individual categories.

Similar results were obtained when the question was modified and the determinants of WTP for downloading an e-book were examined (Table 8). Thus, even a change in the distribution channel of an e-book does not play a crucial role in users' WTP to download an e-book.

The only significant results that increase the WTP to download an e-book is the use of the book to relax and if the reader has a tablet or PC. These results could be different during specific situations, such as the COVID-19 pandemic, which has not allowed users to go to bookshops. It can be assumed that the reasons for WTP would change significantly with this huge impact on people's lives.

\section{Discussion}

\subsection{E-Book preference}

It was hypothesised that e-book preferences are different a) across age categories and b) for the general population and MLP readers. Hypothesis H1a was supported in that younger MLP readers prefer smartphones and computers for reading e-books while pensioners usually do not

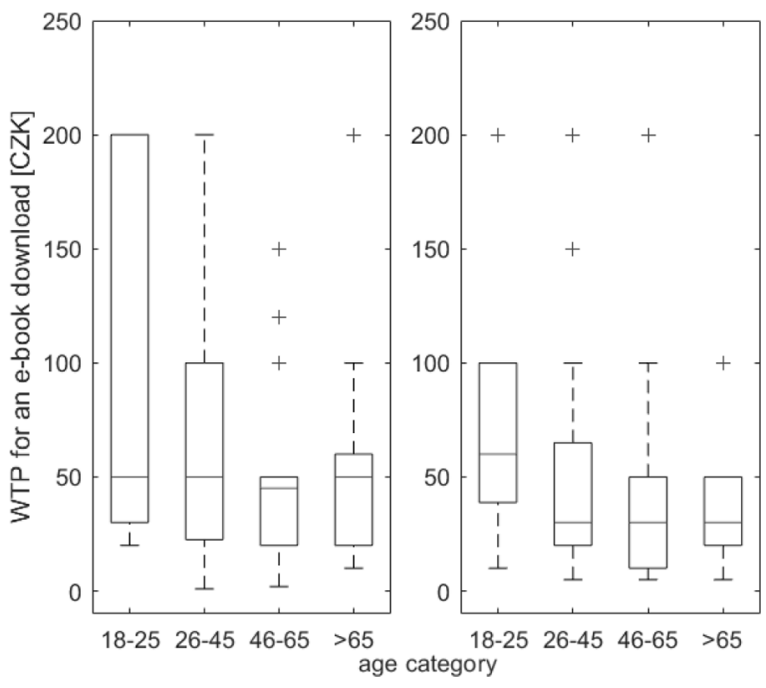

Role of library user preferences d 
EL
39,4

\begin{tabular}{|c|c|c|c|}
\hline Variable & $\begin{array}{l}\text { Standardized } \\
\text { coef. }\end{array}$ & $t$-value & $p$-value \\
\hline Constant term & & 3.490 & $0.001^{* * * *}$ \\
\hline Sex & -0.378 & -2.993 & $0.004^{* * * *}$ \\
\hline Education & -0.298 & -2.852 & $0.005^{* * * *}$ \\
\hline Reading activity - books & -0.125 & -0.940 & 0.350 \\
\hline Reading activity - e-books & -0.019 & -0.146 & 0.884 \\
\hline Preferred way of obtaining e-books - Buy an e-book & -0.008 & -0.087 & 0.931 \\
\hline Preferred way of obtaining e-books - Download a free e-book & -0.071 & -0.713 & 0.478 \\
\hline Preferred way of obtaining e-books - Loan an e-book from a library & 0.100 & 0.995 & 0.322 \\
\hline Preferred way of obtaining e-books - Otherwise & -0.030 & -0.303 & 0.763 \\
\hline Reasons for using e-books - school reading & -0.034 & -0.289 & 0.773 \\
\hline Reasons for using e-books - professional literature & 0.358 & 3.424 & $0.001^{* * * *}$ \\
\hline Reasons for using e-books - reading to children & 0.053 & 0.561 & 0.576 \\
\hline Reasons for using e-books - work duties & 0.093 & 0.960 & 0.340 \\
\hline Reasons for using e-books - relax and other & -0.060 & -0.654 & 0.515 \\
\hline Used device - smartphone & -0.123 & -1.130 & 0.262 \\
\hline Used device - tablet & 0.119 & 1.186 & 0.239 \\
\hline Used device - PC & -0.239 & -1.788 & $0.077^{*}$ \\
\hline Used device - e-book reader & 0.008 & 0.065 & 0.948 \\
\hline Registered reader & 0.043 & 0.428 & 0.670 \\
\hline Economic activity & 0.084 & 0.832 & 0.408 \\
\hline Income & -0.074 & -0.699 & 0.486 \\
\hline Age category & -0.015 & -0.098 & 0.922 \\
\hline$R$ & 0.620 & & \\
\hline$R^{2}$ & 0.384 & & \\
\hline Adj. $R^{2}$ & 0.229 & & \\
\hline
\end{tabular}

Table 7.

Determinants of WTP for an e-book loan

Notes: *Significant at $p<0.10 ; * *$ significant at $p<0.05 ; * * *$ significant at $p<0.01$

have access to these technical devices, which is an obstacle (and at the same time, this result raises the need for libraries to support these people). It can be generally concluded that a laptop or $\mathrm{PC}$ is the most preferred way to read e-books for an older population.

Information and communication technologies have a significant influence on user behaviour and preferences, even in the case of electronic public library services, which have been increasing their e-book offerings over the last ten years. They have been responding to the growing demand of users; namely, readers. However, this is not the case in all countries. For example, in the US, the share of e-books available in US libraries has almost doubled, from $38.3 \%$ in 2007 to $67.2 \%$ in 2011 and 90\% in 2019 (American Library Association, 2012, 2019). In the EU, the situation is similar; now at a 92.3\% rate (Statista Research Department, 2020).

However, the preference for e-books can also be measured by the e-book market share. In the EU, it was $21 \%$ in 2017, with the trend continuing to grow. Thus, the demand for these services and e-reading is higher and is likely to increase substantially. According to the Statista Research Department (2020), the share of e-book sales increased from 4.5\% in 2013 to $21 \%$ in 2017.

This trend is also supported by Hsiao and Chen's (2017) research. The authors concluded that users who have an "e-reading habit" are more willing to influence readers' intentions to use digital products or services. Stejskal et al. (2020) came to the same conclusion. Further research supports these claims and complements them with determinants of user preferences in favour of e-books. For example, Wahid et al. (2011) stated that e-book preference is greater when users combine their user behaviour with environmental 


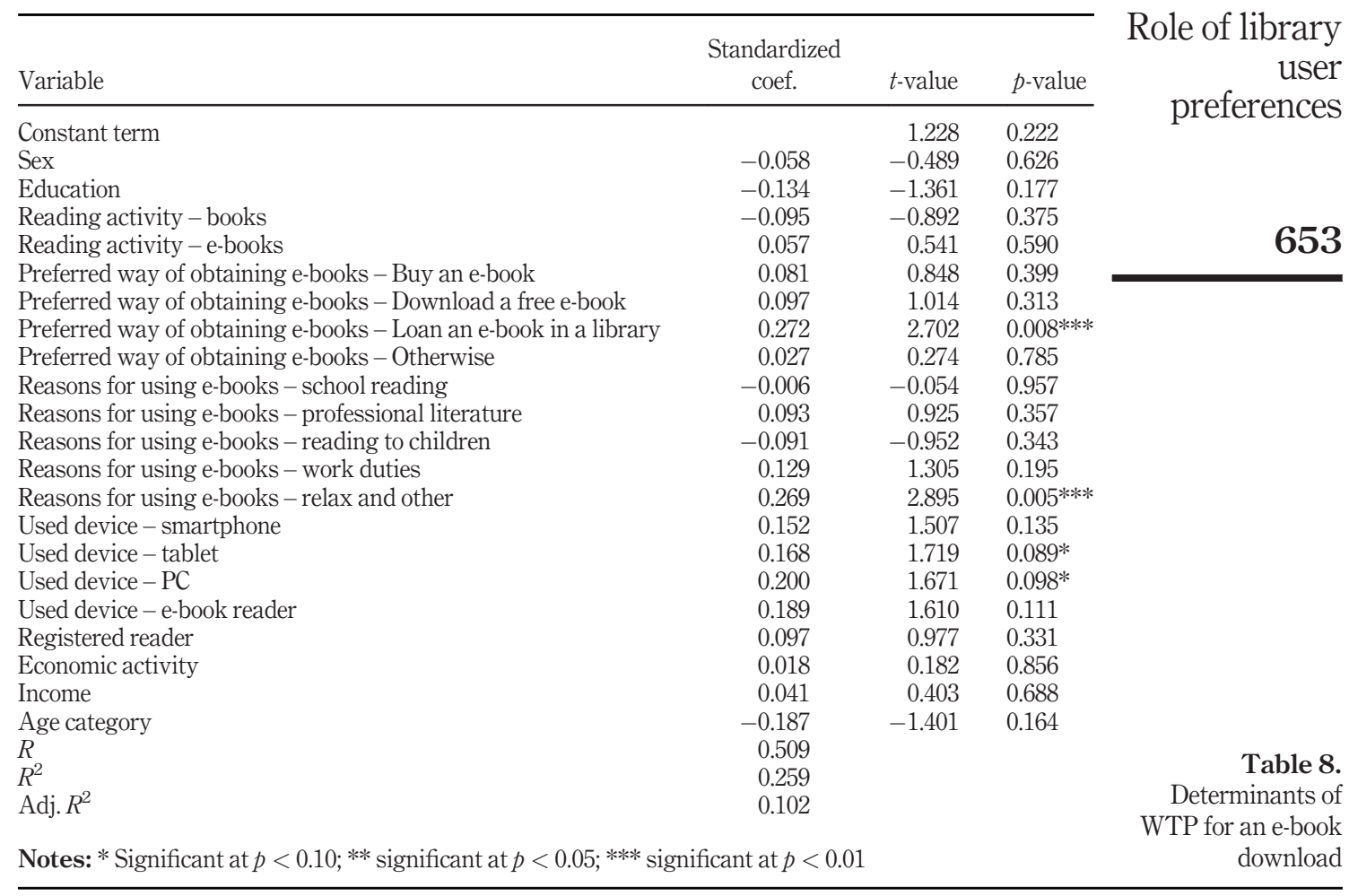

consequences. If they read e-books, the environment will not be burdened by the demand for paper books, which the industry must produce from natural resources. This is supported by the conclusions of Chowdhury (2012) and Guccio et al. (2017).

This trend is also confirmed by statistics from the Czech book market. In 2018 and 2019, this market recorded a significantly higher supply of e-books; compared to 2018, sales of ebooks increased by $12 \%$ year-on-year (Association of Czech Booksellers and Publishers, 2019).

However, the current Covid-19 pandemic situation has significantly changed these results of the studies and statistics. Due to the restrictions, there has been a significant increase in interest in e-books, undoubtedly in all countries. The impact of this pandemic situation will be the subject of future research.

Young people and students tend to adopt new IT services, as confirmed by results of this study. Young people (i.e. up to 26 years) are more willing to consume e-books and use them on smartphones, primarily for school purposes; later (when they reach the older age category) they keep this habit and move from school reading to leisure literature as well as, to a lesser extent, professional literature. It can also be concluded that young readers are more willing to pay for the use of information services. Hsiao and Chen's (2017) findings support this conclusion, and they added that content is a decisive motivator for young readers and only then do young people evaluate it according to the value-on-money rule.

Based on the presented results, it is possible to recommend library management to focus their strategies on creating a sufficient supply of e-books for young readers, using appropriate communication tools and benefiting from the fact that young people are aware 
$\mathrm{EL}$ 39,4

\section{4}

of the library services value and are willing to pay for them. To increase the preference of other groups of readers in e-books, it is still necessary to make great progress in IT literacy, removing all barriers. Even in this case, it is not possible to expect a fundamentally large change in the share of e-book users among the older, economically active population. As the results show, cultural maturity, customs, traditions, and a certain degree of readers' sentiment play a crucial role here.

\subsection{Number of e-books per year}

When returning to the second hypothesis concerning differences in demand for e-books, it can be concluded that the hypotheses were supported; younger MLP readers were the most frequent users of e-books whereas the lowest demand was observed for the older MLP readers. For the general population, demand for e-books was more consistent across age categories.

Gibbons (2001) found that $67 \%$ of respondents read at least one e-book in a year (using e-reader devices); in addition, respondents prefer e-books when reading common popular fiction and nonfiction. The Pew Research Center (2014) determined that $47 \%$ of young Britons (aged 18-30) prefer e-books (reading at least one in a year). There is a growing trend in the popularity of e-books among young people; in 2012, 31\% enjoyed e-books, compared to only $25 \%$ in 2011 (Hsiao and Chen, 2017).

In this discussion, users' overall willingness to use e-books was limited by individuals' traditions and strong habits. Some reject e-books because of the need to "feel the paper in their hands when reading". This sentimental relationship to paper books was also described by Sottong (1999) when he wrote "the best imaging technology cannot surpass printing on paper” (p. 51). Sellen and Harper's (2003) conclusion also supports this finding. The results of the presented research record these results in the Czech environment.

Limits also stem from the availability of e-books, where a large number is protected by copyright, complex negotiations are needed, and the books would be electronically accessible (Blades, 2005). Therefore, for example, libraries produce e-books that are not protected (copyright has expired). This is the case with the Municipal Library in Prague which produces several dozen books every year. It provides them for free to everyone on its website. Newly published books are currently provided in all versions (i.e. both paper book and e-book). This research has demonstrated that readers prefer foreign language fiction and professional literature as well as books written in Czech as a substitute for paper books.

Another reason why the share of e-book users is so small is the barriers against the spread of e-books. Chu (2003) defined barriers against e-books as being hard to read and browse, needing special equipment, and facing additional costs on the user's side. A number of studies have related perceived barriers to a specific group. For example, Pierard et al. (2020) dealt with e-books in school teaching. Their results confirmed various barriers that make it difficult for students to orient themselves, copy, and create notes directly in the text. Friedman (2011) added three other reasons that reduce the willingness to obtain e-books, this time in a commercial way. One of the reasons is the accessibility of the e-book on the Web (for example, in an effort to limit borrowing to only a month, being difficult to register), as well as many formats and e-readers with which readers are unfamiliar. The last barrier is brand loyalty (e.g. Kindle or PocketBook). If a library or publisher's offer is not compatible with this brand, the user will not accept or purchase the e-book. Other reasons that limit shopping and user behaviour towards e-books are described in Shim et al. (2016). An important determinant of e-book consumption is price.

Czech e-book readers are quite a specific group. In the period when e-readers started to be available on the market, the low economic power of the population was a barrier to 
expansion in the Czech Republic. In addition, the speed of technical devices development on which it is possible to read e-books and other documents is very fast. Today, everyone has a phone or tablet and can read e-books. During this period, the availability of e-books and their market price are the biggest barriers here. Czech readers have little awareness of the range of e-books provided by public libraries. In addition, readers are reluctant to pay for the e-book. This is one of the fundamental barriers to the spread of e-books in the Czech Republic.

\section{Role of library user preferences}

655

\subsection{Willingness to pay for e-book services}

The third hypothesis was supported in that MLP readers are less willing to pay for downloading and borrowing e-books. The WTP of the youngest age category (18-25 years) was substantially higher than those of the remaining age categories.

Lu and Hsiao (2010) examined users' WTP for electronic services. In general, they found that users are willing to pay for this type of service if the services have a perceived value and positive attitude. Berger et al. (2015) used the WTP approach to analyse the WTP for information provided on the Internet (in the form of newspapers). They concluded that the low WTP is determined primarily by information provided free of charge. They also found that the lower WTP is also related to a lower appraisal of online formats. As in this study, WTP was determined by electronic devices for reading, desirability, and quality content. Acharya and Lee (2018) published similar results.

These results are consistent with those of Hsiao and Chen (2017), who suggested that content and price are the main advantage and victim of e-book subscription services. Their results confirmed that the expected electronic content has a significant effect on the perceived value of the e-book and the perceived price has a negative effect on the perceived value. Results present the novel approach of Czech readers, whose main determinant of WTP is not the content, but the price and method of payment (allocation). This supports the conclusions of Albanese and Milliot (2015), who postulated that an important factor in users' decisions is the method of payment for the e-service. Some people prefer a cheaper annual lump sum whereas others may charge small regular fees. The decision to pay depends on their reading or payment habits, as the results of this study show.

This finding implies that creators and producers of e-books (both commercial producers and public libraries) should be able to classify their users with the relevant payment preferences to offer those users a specific price as a reward. In addition, they should closely monitor the pricing strategies of their competitors so that they respond quickly to changes in the market.

\section{Conclusions}

This paper dealt with e-books, their use, barriers to greater dissemination and users' WTP for the use of e-books. The views of readers and the general population were compared in this case study conducted in the Czech Republic. This study was designed based on age categories to provide valuable information for library management. Based on these findings, it is possible to define recommendations for acquisition policy; book management can more responsibly decide whether to offer e-books or what to do for their greater dissemination among readers.

This study provides several contributions in terms of both theory and practice. At the theoretical level, the methodology used represents an extension of existing knowledge. It offers experience useful for designing other methodological approaches to analyse e-books or any e-content. Future researchers can use the published conclusions of this study and build their hypotheses or scientific questions on it. User behaviour of library services will 
EL 39,4

not change much depending on age; it is strongly determined primarily by upbringing and education, but also customs and culture in the country. The results of this study are, therefore, significant and can be used for international comparisons, as they clearly complement the current state of knowledge in this area.

The practical contributions of the study are as follows. As mentioned several times above, public libraries need to know readers' preferences to define strategic plans for the development of the library collection as well as other services (typically e-services) that public libraries will provide in the future. Even Czech libraries are faced with the question of whether to preserve paper books to a greater extent or start providing (or even producing on their own) e-books. The results of the study suggest that e-books still have a complementary function. For younger people, it is a welcome modern tool for obtaining and storing information. They are willing to pay for this service. This study also confirmed that barriers to expanding the use of e-books include the lack of availability of e-readers (or other equipment) and low IT literacy. The low WTP for an e-book at an older age also stems from social reasons (lower pensions). However, these reasons are also beginning to disappear, and significant changes can be expected in this area in the future. This should be further examined by future research dealing with the dynamically growing offer of e-books and public support for the accessibility of e-books in public libraries. This area must be examined to better understand the WTP for such a book (a suitable way to verify readers' interest in such a book) and simultaneously provide the basis for decisions on the effective allocation of public money. Future research may also be focused on changing user behaviour due to the Covid-19 pandemic. However, the study should focus not only on changing the behaviour and expectations of readers but also on changing the supply of public libraries, which has been modified under the pressure of this extraordinary situation.

\section{References}

Acharya, B. and Lee, J. (2018), “Users' perspective on the adoption of e-learning in developing countries: the case of Nepal with a conjoint-based discrete choice approach", Telematics and Informatics, Vol. 35 No. 6, pp. 1733-1743.

Ahmad, P. and Brogan, M. (2016), "E-book user behaviour in academic libraries: the role of user agents in perception and satisfaction”, Malaysian Journal of Library and Information Science, Vol. 21 No. 3, pp. 95-109.

Albanese, A. and Milliot, J. (2015), “After Oyster, what's next for e-book subscriptions?”, available at: www.publishersweekly.com/pw/by-topic/digital/Apps/article/68193-after-oyster-what-s-nextfor-e-book-subscriptions.html (accessed 20 November 2020).

American Library Association (2012), "State of America's libraries report 2012: new focus on E-Books: libraries deepen E-book engagement”, available at: https:/alair.ala.org/bitstream/handle/11213/ 7869/201200_AmLibSupplement_State-of-Americas-Libraries-Report-2012.pdf (accessed 28 April 2021).

American Library Association (2019), "State of America's libraries report 2019”, available at: www.ala. org/news/state-americas-libraries-report-2019 (accessed 28 April 2021).

Ashcroft, L. (2011), "Ebooks in libraries: an overview of the current situation", Library Management, Vol. 32 Nos 6/7, pp. 398-407.

Ashcroft, L. and Fong, S. (2005), "The impact of ebooks and elearning on academic library services", in Achleitner, H. and Dimchev, A. (Eds), Libraries, Globalisation and Cooperation, Emporia State University, Emporia, KS, pp. 219-227.

Association of Czech Booksellers and Publishers (2019), Report on the Czech Book Market 2018/2019 (in Czech). 
Bansal, G. (2011), "E-book usage: role of environmental consciousness, personality and past usage", Journal of Computer Information Systems, Vol. 52 No. 2, pp. 93-104.

Berger, B., Matt, C., Steininger, D.M. and Hess, T. (2015), "It is not just about competition with 'free': differences between content formats in consumer preferences and willingness to pay", Journal of Management Information Systems, Vol. 32 No. 3, pp. 105-128.

Berry, L.L., Seiders, K. and Grewal, D. (2002), "Understanding service convenience”, Journal of Marketing, Vol. 66 No. 3, pp. 1-17.

Blades, H. (2005), "The electronic book: some thoughts on the present and the future", Private Library, Vol. 8 No. 4, pp. 148-152.

Cameron, S. (2019), "Cultural economics, books and reading", Journal of Cultural Economics, Vol. 43 No. 4, pp. 517-526.

Carroll, A.J., Corlett-Rivera, K., Hackman, T. and Zou, J. (2016), "E-book perceptions and use in STEM and non-STEM disciplines: a comparative follow-up study", Portal: Libraries and the Academy, Vol. 16 No. 1, pp. 131-162.

Catenazzi, N. (1997), "The evaluation of electronic book guidelines from two practical experiences", Journal of Educational Multimedia and Hypermedia, Vol. 6 No. 1, pp. 91-114.

Chen, C.C. (2012), "Identifying drivers for adoption intention in RFID service", International Journal of Mobile Communications, Vol. 10 No. 3, pp. 231-247.

Chou, S.C., Stu, J. and Lin, Y. (2010), "Determinants of e-book readers adoption and continuation: a comparison of pre-adoption and post-adoption beliefs", 5th International Conference on Computer Sciences and Convergence Information Technology, IEEE, pp. 853-856.

Chow, A. and Tian, Q. (2021), "Public libraries positively impact quality of life: a big data study", Public Library Quarterly, Vol. 40 No. 1, pp. 1-32.

Chowdhury, G. (2012), "How digital information services can reduce greenhouse gas emissions", Online Information Review, Vol. 36 No. 4, pp. 489-506.

Chu, H. (2003), "Electronic books: viewpoints from users and potential users", Library Hi Tech, Vol. 21 No. 3, pp. 340-346.

Cumaoglu, G., Sacici, E. and Torun, K. (2013), "E-book versus printed materials: preferences of university students”, Contemporary Educational Technology, Vol. 4 No. 2, pp. 121-135.

Davis, F.D. (1989), "Perceived usefulness, perceived ease of use, and user acceptance of information technology”, MIS Quarterly, Vol. 13 No. 3, pp. 319-340.

Dillon, D. (2001), "E-books: the university of Texas experience, part 1", Library Hi Tech, Vol. 19 No. 2 , pp. 113-125.

Foasberg, N.M. (2011), “Adoption of e-book readers among college students: a survey”, Information Technology and Libraries, Vol. 30 No. 3, pp. 108-128.

Friedman, J. (2011), "3 Barriers you must eliminate to maximize E-book sales”, available at: www. writersdigest.com/digitization-new-technology/3-barriers-you-must-eliminate-to-maximize-e-booksales (accessed 20 November 2020).

Fujiwara, D., Lawton, R.N. and Mourato, S. (2019), "More than a good book: contingent valuation of public library services in England”, Journal of Cultural Economics, Vol. 43 No. 4, pp. 639-666.

Gibbons, S. (2001), "Ebooks: some concerns and surprises", Portal: Libraries and the Academy, Vol. 1 No. 1, pp. 71-75.

Godwin-Jones, R. (2007), "E-texts, mobile browsing, and rich internet applications", Language Learning and Technology, Vol. 11 No. 3, pp. 8-13.

Guccio, C., Sacerdotti, S.L. and Rizzo, I. (2017), “An empirical investigation of cultural travellers' preferences and behaviours in a destination with mixed environmental features", Enhancing Participation in the Arts in the EU, Springer, Cham, pp. 249-265.

Role of library user preferences 
EL 39,4

Hawkins, D.T. (2002), "Electronic books: reports of their death have been exaggerated”, Online, Vol. 26 No. 4, pp. 42-48.

Hsiao, K.L. and Chen, C.C. (2017), "Value-based adoption of e-book subscription services: the roles of environmental concerns and reading habits", Telematics and Informatics, Vol. 34 No. 5, pp. 434-448.

Huang, L.C., Shiau, W.L. and Lin, Y.H. (2017), "What factors satisfy e-book store customers? Development of a model to evaluate e-book user behavior and satisfaction”, Internet Research, Vol. 27 No. 3, pp. 563-585.

Jeong, H. (2012), "A comparison of the influence of electronic books and paper books on reading comprehension, eye fatigue, and perception”, The Electronic Library, Vol. 30 No. 3, pp. 390-408.

Kendall, M. (1996), "Public library services for older adults”, Library Review, Vol. 45 No. 1, pp. 26-29.

Kim, D. (2018), "Consumer welfare of informative messages via mobile instant messenger: a case of KakaoTalk's info-talk", Telematics and Informatics, Vol. 35 No. 6, pp. 1643-1655.

Kim, G. (2011), "A critical review of valuation studies to identify frameworks in library services", Library and Information Science Research, Vol. 33 No. 2, pp. 112-119.

Kim, J., Seo, J., Zo, H. and Lee, H. (2020), "Why digital goods have not replaced traditional goods: the case of e-books”, Journal of Enterprise Information Management, Vol. 34 No. 3, pp. 793-810.

Ko, Y.M., Shim, W., Pyo, S.H., Chang, J.S. and Chung, H.K. (2012), "An economic valuation study of public libraries in Korea”, Library and Information Science Research, Vol. 34 No. 2, pp. 117-124.

Kurata, K., Ishita, E., Miyata, Y. and Minami, Y. (2017), "Print or digital? Reading behavior and preferences in Japan", Journal of the Association for Information Science and Technology, Vol. 68 No. 4, pp. 884-894.

Lai, J.Y. and Chang, C.Y. (2011), "User attitudes toward dedicated e-book readers for reading”, Online Information Review, Vol. 35 No. 4, pp. 558-580.

Lee, S.J. and Chung, H.K. (2012), "Analyzing altruistic motivations in public library valuation using contingent valuation method", Library and Information Science Research, Vol. 34 No. 1, pp. $72-78$.

Lin, P.H., Su, Y.N. and Huang, Y.M. (2019), "Evaluating reading fluency behavior via reading rates of elementary school students reading e-books", Computers in Human Behavior, Vol. 100, pp. 258-265.

Liu, Q., Zhang, X. and Li, Y. (2020), “The influence of information cascades on online reading behaviors of free and paid e-books", Library and Information Science Research, Vol. 42 No. 1, p. 101001.

Lu, H.P. and Hsiao, K.L. (2010), "The influence of extro/introversion on the intention to pay for social networking sites", Information and Management, Vol. 47 No. 3, pp. 150-157.

Martindale, G., Willett, P. and Jones, R. (2015), "Use and perceptions of e-books in Derbyshire libraries”, Library Review, Vol. 64 Nos 1/2, pp. 2-20.

Min, S.H., Kim, H.Y., Kwon, Y.J. and Sohn, S.Y. (2011), "Conjoint analysis for improving the e-book reader in the Korean market", Expert Systems with Applications, Vol. 38 No. 10, pp. 12923-12929.

Noh, Y. (2020), "A study of the evaluation of a library's economic value based on the users' and librarians' perceptions", The Electronic Library, Vol. 38 No. 3, pp. 561-596.

Pew Research Center (2014), "Most adults read a book in the past year: print remains most popular, but e-reading is on the rise", available at: www.pewinternet.org/2014/01/16/e-reading-rises-asdevice-ownership-jumps/e-readers1/ (accessed 20 November 2020).

Pierard, C., Svihla, V., Clement, S.K. and Fazio, B.S. (2020), "Undesirable difficulties: investigating barriers to students' learning with ebooks in a semester-length course", College and Research Libraries, Vol. 81 No. 2, pp. 170-192.

Prokop, V. and Stejskal, J. (2020), "Cross-generation analysis of e-book consumers' preferences - a prerequisite for effective management of public library", Information, Vol. 11 No. 2, p. 72. 
Rao, K.N., Kumar, S. and Tripathi, M. (2018), "E-book and print book price and desirability for university libraries: a comparative study", The Electronic Library, Vol. 36 No. 1, pp. 82-102.

Richter, A. and Courage, M.L. (2017), "Comparing electronic and paper storybooks for preschoolers: attention, engagement, and recall", Journal of Applied Developmental Psychology, Vol. 48, pp. 92-102.

Rogers, E.M. (2003), Diffusion of Innovations, 5th ed., Free Press, New York, NY.

Sainsbury, L. (1996), "Looking to the future: alternative forms of children's books: a discussion of children's use of electronic and audio books", British Library Research and Innovation Report, Vol. 14, pp. 230-239.

Salloum, S.A. and Shaalan, K. (2018), "Adoption of e-book for university students", In Proceedings from International Conference on Advanced Intelligent Systems and Informatics, Springer, Cham, pp. 481-494.

Schilit, B. (1999), "Why e-read? Finding opportunities in the merger of paper and computers", The Future of Print Media, available at: https://sites.google.com/site/schilit/Why-e-Read.pdf (accessed 20 November 2020).

Sellen, A.J. and Harper, R.H. (2003), The Myth of the Paperless Office, MIT Press, Cambridge, MA.

Shim, D., Kim, J.G. and Altmann, J. (2016), "Identifying key drivers and bottlenecks in the adoption of ebook readers in Korea", Telematics and Informatics, Vol. 33 No. 3, pp. 860-871.

Shrimplin, A.K., Revelle, A., Hurst, S. and Messner, K. (2011), “Contradictions and consensus - clusters of opinions on e-books", College and Research Libraries, Vol. 72 No. 2, pp. 181-190.

Sin, S.C.J. and Vakkari, P. (2015), "Perceived outcomes of public libraries in the US", Library and Information Science Research, Vol. 37 No. 3, pp. 209-219.

Sottong, S. (1999), “Don't power up that e-book just yet”, American Libraries, Vol. 30 No. 5, pp. 50-53.

Statista Research Department (2020), "E-book market share in Europe 2013-2017", available at: www. statista.com/statistics/292092/ebook-market-share-europe/ (accessed 20 November 2020).

Stejskal, J. and Hajek, P. (2015), "Effectiveness of digital library services as a basis for decision-making in public organizations", Library and Information Science Research, Vol. 37 No. 4, pp. 346-352.

Stejskal, J., Hájek, P. and Cerny, P. (2020), “A novel methodology for surveying children for designing library services: a case study of the municipal library of Prague", Journal of Librarianship and Information Science, online-first, Vol. 53 No. 2, p. 0961000620948568.

Stejskal, J., Hájek, P. and Řehák, T. (2016), "The economic value of book loans - the case of the municipal library of Prague", Libri, Vol. 66 No. 4, pp. 303-311.

Vassiliou, M. and Rowley, J. (2008), "Progressing the definition of 'e-book”, Library Hi Tech, Vol. 26 No. 3, pp. 355-368.

Wadley, A.L., Broady, J.E. and Hayward, T.E. (1997), “An evaluation of current public library service to the full-time employed”, Library Management, Vol. 18 No. 4, pp. 205-215.

Wahid, N.A., Rahbar, E. and Shwu Shyan, T. (2011), "Factors influencing the green purchase behavior of Penang environmental volunteers", International Business Management, Vol. 5 No. 1, pp. 38-49.

Wang, X., Wang, W., Chai, Y., Wang, Y. and Zhang, N. (2019), "E-book adoption behaviors through an online sharing platform”, Information Technology and People, Vol. 33 No. 3, pp. 1011-1035.

Zhu, Y. (2015), "China at BEA 2015: the E-book market in China”, available at: www.publishersweekly. com/pw/by-topic/industry-news/bea/article/66714-china-at-bea-2015-the-e-book-market-in-china. html (accessed 20 November 2020).

\section{Further reading}

Wearden, S. (1998), "Electronic books: a study of potential features and their perceived value”, Future of Print Media, available at: www.futureprint.kent.edu/articles/wearden02.htm (accessed 20 November 2020).

Role of library user preferences 
EL

39,4

\section{0}

Appendix

Variable Frequency/Mean \pm St. Dev.

a) General population

Sex $\quad$ Male: 565 , female: 536

Age $\quad 48.1 \pm 16.7$ (18-25 years: $120,26-45: 384,46-65: 369$, > 65: 227)

Reading activity in the last 12 months No: 246 , yes: 855 (14 books on average)

Registered reader No: 786, yes: 314

Education Primary: 163, lower secondary: 453, upper secondary: 344,

Economic situation university: 141

Retired: 331 , econ
unemployed: 174

Net income of household in CZK $\quad<15,000: 184,15,000-30,000: 433,30,000-45,000: 300,45,000$

City size

60,000: $121,60,000-75,000: 29,>75,000: 33$

$<2,000: 241,2,000-10,000: 251,10,000-100,000: 376,>100,000: 233$

b) Readers from the MLP

Sex

Male: 288, female: 1021

Age

Reading activity in the last 12 months

Education

$44.9 \pm 17.0$ (18-29 years: $220,30-49: 559,50-64: 338,>65: 217)$

38.0 books on average

Primary: 44, lower secondary: 46, upper secondary: 482, university: 742

Economic situation Retired: 233, economically active: 786, student: 176, other/

Table A1.

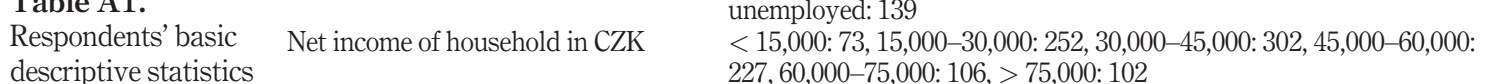
descriptive statistics

\begin{abstract}
About the authors
Jan Stejskal is A Full Professor with the Institute of Economics, Faculty of Economics and Administration, University of Pardubice and Masaryk University, Faculty of Economics and Administration in Brno, Czech Republic. He received PhD in Public and Regional Economics from University of Pardubice in 2007. His current research interests include public economy in the regional scope and view. Especially, he analyses regional policy, tools of the local and regional economic development and public services. His research has been published in leading information science journals. Jan Stejskal is the corresponding author and can be contacted at: jan.stejskal@upce.cz

Petr Hajek is a Full Professor with the Science and Research Centre, Faculty of Economics and Administration, University of Pardubice, Czech Republic. He received PhD in System Engineering and Informatics from University of Pardubice in 2006. His current research interests include modelling economic processes (especially in the field of public economics and public finance). His research has been published in leading information science journals.

Viktor Prokop is an Assistant Professor with the Science and Research Centre, Faculty of Economics and Administration, University of Pardubice, Czech Republic. He received $\mathrm{PhD}$ in Public and Regional Economics from University of Pardubice in 2016. His current research interest include public services and analysis of the efficiency.
\end{abstract}

For instructions on how to order reprints of this article, please visit our website:

www.emeraldgrouppublishing.com/licensing/reprints.htm

Or contact us for further details: permissions@emeraldinsight.com 